\title{
Optimizing Oral Controlled Release Drug Delivery Systems using Experimental Designs
}

\section{Sahilhusen I Jethara ${ }^{1,2 *}$ and Mukesh R Patel ${ }^{2}$}

${ }^{1}$ Research scholar, Gujarat Technological University, Gujarat, India

${ }^{2}$ Shri B. M. Shah College of Pharmaceutical Education and Research, Modasa-383315, Gujarat, India

\begin{abstract}
The number of literature reports on the use of design of experiments optimization in development of drug delivery technology has been piling up steadily. This review article provides an updated bird's eye view survey account on the publications and optimization techniques of different novel controlled release delivery designs for use in oral applications. Such systematic techniques find their use in every type of conventional dosage form and novel drug delivery system. The drug delivery devices investigated for optimization using various designs include oral controlled release tablet. The present manuscript deal with various steps involved in design of experiments optimization methodology using diverse experimental designs. It also deals with a variety of showing literature findings as well as the potential application of such design of experiments procedures on optimization of assorted drug delivery systems. Such an explicit and updated review on drug delivery optimization has not been published anywhere else in the recent past.
\end{abstract}

Keywords: Controlled release; Tablet; Sustained release; Factors; Experimental designs
Abbreviations:
HPMC:
Hydroxypropylmethylcellulose; $\mathrm{Na}$ CMC: Sodium Carboxymethylcellulose; EC: Ethylcellulose; HEC: Hydroxyethylcellulose; DCP: Dicalciumphosphate; PVC: Polyvinylchloride; HPC: Hydroxypropylcellulose; MCC: Microcrystallinecellulose; PEG: Polyethylene Glycols; PVP: Polyvinylpyrrolidone

\section{Introduction}

The use of optimization techniques employing design of experiments (DoE), however, permeated the field of pharmaceutical product/process development around four decades ago. The first literature report on the rational use of optimization appeared in 1967, when a tablet of sodium salicylate was optimized using a factorial designs (FD). Since then, these systematic approaches have been put into practice in the development of drug formulations at steady pace. Despite tremendous advancements in diverse drug delivery approaches, the oral route remains the most "natural" route of drug administration. In addition, because of the low cost of oral therapy, ease of administration, and improved patient compliance associated with oral route, more than $50 \%$ of drug delivery systems available commercially are oral ones. In this context, oral controlled release drug delivery systems are quite popular, offering a number of advantages over conventional dosage forms $[1,2]$. Generally, the controlled release drug delivery systems for oral use are solid dosage forms, based upon the mechanism of diffusion, dissolution, or a blend of both to control the release rate of drug. These include reservoir devices wherein a polymeric membrane surrounds a drug core and matrix devices wherein the dissolved or dispersed drug is distributed uniformly in an inert polymeric matrix. Most DoE literature reports in this category are focused on optimizing the levels of these release rate-controlling polymers. DoE optimization on oral controlled release matrix delivery devices started in the early 1980s. Such devices encompass the inert matrices such as hydrophilic, hydrocolloid, silicone elastomer, and lipid matrices. The common independent variables for all of these have been the quantities of the polymers or other ingredients, while the optimized responses invariably have been the parameters characterizing in vitro dissolution profile. The other response variables that have been optimized include disintegration time, bioavailability, and bioequivalence $[3,4]$.

The literature reports on oral controlled release dosage forms have been compiled in various tables, categorized on the basis of various types of polymers (natural, semi-synthetic, synthetic) and the type of controlled release dosage form (matrices, dispersions, coated tablets). Table 1 depict the use of statistical experimental designs in optimization of oral sustained release (SR) matrices along with the selected drug candidate and various input variables (factors) studied.

Table 1 reports the work on DoE optimization of oral controlled release drug delivery systems, where natural, synthetic or semisynthetic polymers have been taken as factors, invariably to control or modify the release rate of the drug. The natural polymers used comprise isapghula husk, guar gum, xanthan gum, pectin, carrageenan, and alginic acid. Optimization reports on sustained release tablets formulated using synthetic polymers such as acrylates, polymethacrylates, silicone elastomers, and polyethylene glycols (PEG), are shown in Table 1. Apart from polymer level, various other factors that have been optimized include tablet size, compression force, and amount of granulation liquid, lubricant, and glidants. Although most studies focused on optimizing drug release parameters, some studies involved optimization of dissolution evaluation conditions as well. Semisynthetic polymers that frequently have been employed include mainly the cellulose derivatives i.e., hydroxyl-propyl-cellulose (HPC), hydroxyl-propyl-methyl-cellulose (HPMC), hydroxyethylcellulose (HEC), sodium carboxy-methylcellulose (Sodium CMC), and ethylcellulose (EC). Some studies on the gums involve treatment with acid

*Corresponding author: Sahilhusen I. Jethara, Department of Pharmaceutics, Shri B.M.Shah College of Pharmaceutical Education and Research, College Campus, India, Tel: 8460378336; E-mail: sahil.pharm4@gmail.com

Received December 17, 2014; Accepted December 19, 2014; Published January 02, 2015

Citation: Jethara SI, Patel MR (2015) Optimizing Oral Controlled Release Drug Delivery Systems using Experimental Designs. Intel Prop Rights 3: 135 doi:10.4172/2375-4516.1000135

Copyright: @ 2015 Jethara SI, et al. This is an open-access article distributed under the terms of the Creative Commons Attribution License, which permits unrestricted use, distribution, and reproduction in any medium, provided the original author and source are credited. 
Citation: Jethara SI, Patel MR (2015) Optimizing Oral Controlled Release Drug Delivery Systems using Experimental Designs. Intel Prop Rights 3: 135. doi:10.4172/2375-4516.1000135

Page 2 of 6

\begin{tabular}{|c|c|c|c|}
\hline APIs & Investigated Factors & Experimental Designs & Ref. \\
\hline Paracetamol & Carbopol 971P, Carbopol 71G, Tablet size & Factorial Design & [8] \\
\hline Fluoride & HPMC K4M, HPMC K100 LV, Eudragit RL PO & Simplex Lattice Design & [9] \\
\hline Metformin $\mathrm{HCl}$ & Various viscosity grades HPMC, Adhesive type, Lubricant & Response Surface Methodology & [10] \\
\hline Verapamil $\mathrm{HCl}$ & HPMC, $\mathrm{Na}$ CMC & Central Composite Design & [11] \\
\hline Metoprolol tartrate & HPMC, HEC, DCP & Factorial Design & [12] \\
\hline Ketorolac Tromethamine & HPMC: Na CMC Ratio, EC & Factorial Design & [13] \\
\hline Diltiazem HCl & $\begin{array}{l}\text { Various Grades Carrageenan and Cellulose Acetate Propionate, lonic strength, } \\
\text { Buffer concentration }\end{array}$ & Factorial Design & [14] \\
\hline Diltiazem HCl & Succinic Acid-treated Ispaghula Husk, DCP & Factorial Design & [15] \\
\hline Diltiazem $\mathrm{HCl}$ & Guar Gum, Ispaghula Husk & Factorial Design & [16] \\
\hline Diltiazem $\mathrm{HCl}$ & Guar Gum (Modified and Unmodified), DCP & Simplex Lattice Design & [17] \\
\hline Diltiazem HCl & Modified Guar Gum, Succinic Acid, Drug content & Rotatable Central Composite Design & [18] \\
\hline Diltiazem $\mathrm{HCl}$ & Ispaghula Husk, Water, Heating Time & Factorial Design & [19] \\
\hline Ropivacaine & Pectin, EC, Binder & D-Optimal Design & [20] \\
\hline Metoprolol tartrate & HPMC, Lactose: DCP ratio, magnesium Stearate, lubricant blend time, compression force & Face Centered Composite Design & [21] \\
\hline Diclofenac sodium & Ispaghula husk, Lactose, MCC & Simplex Centroid Design & [22] \\
\hline Diclofenac sodium & HPMC of Different Grades & Factorial Design & [23] \\
\hline Diclofenac sodium & Spray-dried Rice Starch, Croscarmellose sodium, magnesium Stearate, compression force & Central Composite Design & [24] \\
\hline Diclofenac sodium & EC, PVC, Talc & Factorial Design & [25] \\
\hline $\begin{array}{l}\text { Chlorpheniramine } \\
\text { maleate }\end{array}$ & $\psi$ Carrageenan, HPMC & Simplex Lattice Design & [26] \\
\hline $\begin{array}{l}\text { Chlorpheniramine } \\
\text { maleate }\end{array}$ & Y-Carrageenan:cross-linked Na CMC, $\alpha$-Lactose monohydrate, DCP & Simplex Mixture Design & [27] \\
\hline $\begin{array}{l}\text { Chlorpheniramine } \\
\text { maleate }\end{array}$ & $\mathrm{Na}$ CMC, HPMC, HPC, HEC & Artificial Neural Networks, Simplex Centroid Design & [28] \\
\hline Calcium phosphate & HPMC K4M, HPMC K10 M, & Simplex Mixture Design & [29] \\
\hline Propranolol $\mathrm{HCl}$ & HPMC, $\mathrm{Na}$ CMC & Simplex Lattice Design, D-Optimal Design & [30] \\
\hline Verapamil $\mathrm{HCl}$ & HPMC, Sodium Alginate & Sequential Simplex Design & [31] \\
\hline Trapidil & HPMC, MCC & Central Composite Design, Artificial Neural Networks & [32] \\
\hline Caffeine, ibuprofen & PEG 6000 and Acacia amount in Core & Factorial Design & [33] \\
\hline Theophylline & HPC, MC, compression force & Central Composite Design & [34] \\
\hline Theophylline & HPMC, HPC, MCC & Simplex Lattice Design & [35] \\
\hline Theophylline & HPMC of Different Grades & Response Surface Methodology & [36] \\
\hline Naftidrofuryl & Guar Gum, Xanthan Gum, MCC, Calcium Phosphate Dihydrate & Simplex Centroid Design & [37] \\
\hline Naftidrofuryl & Xanthan Gum, Guar Gum & Central Composite Design & [38] \\
\hline Misoprostol & HPMC, Na CMC, Lactose & Factorial Design & [39] \\
\hline Alprazolam & Na CMC: Lactose ratio, HPMC 4000: HPMC 100 ratio, & Rotatable Central Composite Design & [40] \\
\hline Atenolol & Various grades Carbopol & Factorial Design & [41] \\
\hline Theophylline & Gelucires, Melting point, HLB, paddle rotation Speed & Factorial Design & [42] \\
\hline $\begin{array}{l}\text { Dextromethorphan } \\
\text { Hydrobromide }\end{array}$ & Polydimethylsiloxane, Silicone to Silica ratio & Full Factorial Design & [43] \\
\hline Potassium chloride & Silicone Elastomer Latex, PEG of Various Grades & Extreme Vertices Design & [44] \\
\hline Phenyl propanolamine & Eudragit NE-40D, MCC, milling of granules before compression & Factorial Design & [45] \\
\hline Ibuprofen & Eudragit (L100, RS, RSPM, RLPM), EC, HPMC, HPMC phthalate & $\begin{array}{l}\text { Principal Component Analysis, Response Surface } \\
\text { Methodology }\end{array}$ & [46] \\
\hline $\begin{array}{l}\text { d-Chlorpheniramine } \\
\text { maleate }\end{array}$ & EC, Eudragit, Magnesium Stearate, Talc & Factorial Design & [47] \\
\hline $\begin{array}{l}\text { Theophylline, Etophylline, } \\
\text { Proxyphylline }\end{array}$ & Gelucire 50/02 \& 50/13 & Response Surface Methodology & [48] \\
\hline Captopril & Glyceryl Monostearate, Groundnut oil & Factorial Design & [49] \\
\hline Ibuprofen & Eudragit S-100, Lubricant to Glidant Ratio, Diluents, compression force & Latin Square Design & [50] \\
\hline Ketoprofen & Eudragit S 100 , Lactose & Box Behnken Design & [51] \\
\hline Chlorpheniramine maleate & Carbopol, PVP, MCC & Extreme Vertices Design & [52] \\
\hline Lobenzarit disodium & Eudragit RS-PO, MCC & Central Composite Design & [53] \\
\hline Aspirin & Eudragit L100, compression force & Central Composite Design & [54] \\
\hline Bumetanide & Polymer, pH Modifiers, Solubility Modifiers & Central Composite Design, D-Optimal Design & [55] \\
\hline Nifedipine, Nimpodipine & Carbopol 934P, Carbopol 971P, Carbopol 974P & Artificial Neural Networks & [56] \\
\hline Naproxen & De-aggregating Agent, Compression Pressure & Box Behnken Design & [57] \\
\hline Didanosine & Eudragit RS-PM: Ethocel 100 Ratio & Doehlert Design & [58] \\
\hline Aspirin & Eudragit RS-PO, compression force & Central Composite Design & [59] \\
\hline Theophylline & PEG 6000, Lactose, Stearic Acid & Response Surface Methodology & [60] \\
\hline
\end{tabular}

Table 1: Optimization reports on oral sustained release tablet formulations. 
Citation: Jethara SI, Patel MR (2015) Optimizing Oral Controlled Release Drug Delivery Systems using Experimental Designs. Intel Prop Rights 3: 135. doi:10.4172/2375-4516.1000135

or alkali to modify the swelling properties of the naturally existing gum and subsequent optimization of their proportion, to be used in SR matrices. Experimental designs have also successfully been employed in the case of the core-in-cup type of compressed SR matrices, studying role of non-swell-able polymers and the other process variables in retarding the release of soluble (caffeine) and insoluble (ibuprofen) drugs employing factorial designs [5-7].

\section{Design of experiments and optimization techniques in pharmaceutical research}

The design of experiments $(D O E)$ is an efficient procedure for planning experiments so that the data obtained can be analyzed to yield valid and objective conclusions. Experimental designs can be defined as the strategy for setting up experiments in such a manner that the information required is obtained as efficiently and precisely as possible. Well-chosen experimental designs maximize the amount of information that can be obtained for a given amount of experimental effort. Optimization of a formulation or process is finding the best possible composition or operating conditions. Determining such a composition or set of conditions is an enormous task, probably impossible and certainly unnecessary. Hence in practice, optimization may be considered as the search for a result that is satisfactory and at the same time the best possible within a limited field of search.

The purpose of optimization is to determine quantitatively the influence of the different factors together on the response variables. The number of levels is usually limited to two, but sufficient experiments are carried out to allow for interaction between factors (Figure 1) [7].

Experimental designs have long been employed to optimize various industrial products and/or processes such as;

- Completely randomized designs (CRD)

- Randomized block designs (RBD)

- Screening Designs since 1946

- Simplex Lattice Design

- Latin squares designs (LSDs)

o Graeco-Latin squares designs

o Hyper-Graeco-Latin squares designs

- Factorial Designs (FDs) since 1926

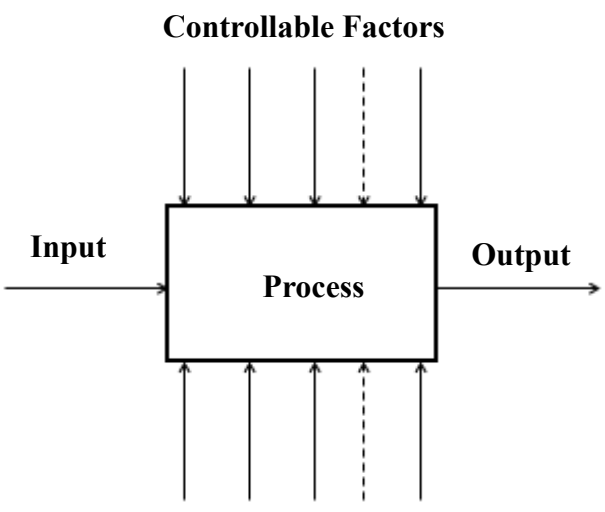

Uncontrollable Factors

Figure 1: Process Models for DOE. o Full factorial designs

o Fractional factorial designs

- Plackett-Burman designs (PBDs)

- Central composite designs (CCDs) since 1951

o Face Centered Composite Design

o Rotatable Central Composite Design

- Box-Behnken designs (BBD)

- Response Surface Methodology (RSM)

- D-Optimal Design (D-OD)

- Simplex Centroid Design (SCD)

- Simplex Mixture Design (SMD) since 1958

- Sequential Simplex Design (SSDs)

- Artificial Neural Networks (ANN)

- Extreme Vertices Design (EVD)

- Doehlert Design

- Principal Component Analysis (PCA)

DOE steps:

- Problem statement

- Choice of factors, levels, and ranges

- Choice of response variable(s)

- Choice of experimental design

- Performing the experiment

- Statistical analysis

- Conclusions and recommendations

STEPS:

\begin{tabular}{l}
$\begin{array}{c}\text { Defining objectives of study and planning } \\
\text { the experiment }\end{array}$ \\
$\begin{array}{c}\text { Screening of factor and factor influence } \\
\text { studies }\end{array}$ \\
$\begin{array}{c}\text { Response surface methodology using } \\
\text { experimental design }\end{array}$ \\
$\begin{array}{c}\text { Formulation and evaluation of drug delivery } \\
\text { system as per experimental design }\end{array}$ \\
Validation of design of experiment design \\
Optimization by optimization techniques \\
\hline \&
\end{tabular}

DOE applications in process development:

- Improve process yield

- Reduce variability

- Reduce development time

- Reduce overall costs

\section{DOE objectives:}

- Determine influential variables (factors) 
- Determine where to set influential factors to optimize response

- Determine where to set influential factors to minimize response variability

- Determine where to set influential factors to minimize the effect of the uncontrollable factors.

\section{DOE applications in design:}

- Evaluate and compare alternatives

- Evaluate material alternatives

- Product robustness

- Determine key design parameter.

\section{Optimizing Oral Controlled Release Tablet Fomulations}

An exhaustive literature search carried out by the authors in pharmaceutical journals and texts reveals that the DoE optimization techniques have been employed for almost all of these dosage forms, ranging from the simple conventional ones to that of the most intricate novel DDS. The updated literature reports unequivocally point out the increasing application of DoE techniques, with a significant shift in the focus of the formulator from optimization of the conventional formulations to that of the modern drug delivery devices [7].

\section{Current and Future Developments}

With the advent of newer, sophisticated technologies, the task of drug delivery has become more intricate, involving a greater number of resources in terms of cost, time, and energy. To circumvent these developmental hiccups, adoption of DoE analytical tools is prudently called for. Particularly, when finding the correct compromise is not straight forward, a pharmaceutical scientist should mandatorily consider the use of optimization studies.

DoE techniques have been applied with fruition on almost all kinds of drug delivery systems, not only for optimizing the formulations but their processes too. Nevertheless, there are many new drug delivery applications awaiting demonstrations. The pivotal benefits of DoE have not been thoroughly investigated in some newer drug delivery areas such as gene delivery, peptide delivery, reverse micellar systems, dendrimer based delivery systems and the like. Understanding the formulation or process variables rationally using experimental designs will help in achieving the desired goals with phenomenal ease. Experimental designs can prove to be useful, even if the primary aim is not the selection of the optimum formulation, because it tends to reveal the degree of improvement in the product characteristics as a function of the change in any excipient or process parameter(s). The major impediment in using DoE has been to envision the entire exercise as a whole. The more the formulator knows about the system, the better it can be defined, and the higher the precision with which it can be modified. The difficulties in optimizing a pharmaceutical formulation are due to the difficulty in understanding the real relationship between casual and individual responses. DoE studies can come to the rescue of the formulator, yielding much better prognostic abilities. Once the empirical relationship between the cause and the effect is unraveled, the developmental or post-developmental thoughts can be realized quite rapidly as well as rationally. Defining the relationship between the formulation or process variables and quality traits of the formulation is almost an impossible task without the application of an apt design model. Trial and error methods, in this regard, can never allow the formulator to know how close any particular formulation is to optimal drug delivery solution. This would provide the desired impetus to the product development scientist, facilitating further evolution of research on oral controlled release drug delivery innovations and nextgeneration product launches.

\section{Conclusions}

The literature search indubitably ratifies the steadily increasing popularity of DoE in drug delivery optimization. Verily, the number of optimization studies would be much higher in the drug industry, where DoE methods are applied much more frequently. Because only a miniscule fraction of industrial studies is reported, most investigations remain as only in-house information. Nevertheless, the DoE usage is far from being adopted as a standard practice. Many more endeavors have to be undertaken to highlight the enormous benefits of these techniques before this can happen as a global trend. With the easy availability and affordability of DoE software, these powerful tools can be implemented with the simple click of a mouse. However, there are some key issues that depend upon the experimenter but not upon the software. These include choosing suitable responses (output variables) and factors (input variables), setting appropriate factor ranges or levels, managing the experimentation, interpreting numeric outcomes and graphic manifestations of the findings, presenting the results, and finally deciding whether to continue further with process optimization or just run confirmatory experiment(s) to validate DoE. If the experimenter has not endeavored DoE as yet or if a significant jump in information and impact in production capability has not yet been obtained, it is the most opportune time to get started. Eventually, the day will come when the benefits of DoE would be harvested by drug industry and research to their fullest advantage. Providing a relatively pithy overview, this article thus endeavors to act as a disambiguation of knowledge, and knows how to guide and provide ideas to the product development scientists in formulating varied oral controlled release drug delivery systems. I hope that my effort is going to find new application or new idea in nearer future.

\section{Acknowledgements}

The author would like to thank Dr. M. R. Patel for his comments.

\section{References}

1. Lobenberg R, Amidon GL, Vieira M (2000) Solubility as a limiting factor to drug absorption. In: Dressman JB, Lennernas H, editors. Oral Drug Absorption: Prediction and Assessment. New York: Marcel Dekker.

2. Kumar MNVR (2000) Nano and microparticles as controlled drug delivery devices. J Pharm Pharmaceut Sci 3: 234-258.

3. Robinson JR, Lee VHL (1987) Controlled Drug Delivery: Fundamentals and Applications. New York: Marcel Dekker.

4. Harris MR, Schwartz JB, McGinity JW (1985) Optimization of a slow release tablet formulation containing sodium sulphathiazole and a montmorrilonite clay. Drug Dev Ind Pharm 11: 1089-1110.

5. Franz RM, Sytsma JA, Smith BP, Lucisano LJ (1987) In vitro evaluation of a mixed polymeric sustained release matrix using RSM. J Control Release 5 : 159-172.

6. Joly F, Brossard C (1987) Development of a hydrophilic matrix for theophylline. Part 1. Physical and mechanical properties of materials and optimization of formulation. STP Pharm. Pratiques 3: 556-568

7. Bhupinder S, Manju D, Vandana S, Naveen A (2005) Optimizing drug delivery systems using systematic "design of experiments." part II: Retrospect and prospects. Crit Rev Ther Drug Car Sys 22: 215-293.

8. Parojcic J, Duric Z, Jovanovic M, Ibric S (2004) An investigation into the factors influencing drug release from hydrophilic matrix tablets based on nove carbomer polymers. Drug Deliv 11: 59-65. 
Citation: Jethara SI, Patel MR (2015) Optimizing Oral Controlled Release Drug Delivery Systems using Experimental Designs. Intel Prop Rights 3: 135. doi:10.4172/2375-4516.1000135

9. Tillotson J, Sakr A (2004) Application of multiple-response optimization to fluoride release from an extended-release matrix tablet. Pharm Ind 66: 601606 .

10. Li J, Dong E, Li H, Pan W (2003) Studies on the factors influencing metformin hydrochloride release from matrix tablets and the optimization of formulation. Shenyang Yaoke Daxue Xuebao 20: 88-92.

11. Singh B, Buhary MS, Ahuja N, Chaturvedi SC (2002) Formulation optimization and characterization of hydrophilic matrices of verapamil hydrochloride using central composite design (CCD). In: Proceedings of 54th Indian Pharmacutical Congress; Pune, India.

12. Minarro M, Garcia-Montoya E, Sune-Negre JM, Tico JR (2001) Study of formulation parameters by factorial design in metoprolol tartrate matrix systems. Drug Dev Ind Pharm 27: 965-973.

13. Vatsaraj N, Zia H, Needham T (2002) Formulation and optimization of a sustained-release tablet of ketorolac tromethamine. Drug Deliv 9: 153-159.

14. Lewis GA, Chariot M (1991) Non classical experimental designs in pharmaceutical formulations. Drug Dev Ind Pharm 17: 1551-1570.

15. Gohel MC, Amin AF, Chhabaria MT, Panchal MK, Lalwani AN (2005) Modulation of drug release rate of diltiazem- $\mathrm{HCl}$ from hydrogel matrices of succinic acidtreated ispaghula husk. Pharm Dev Technol 5: 375-381.

16. Gohel MC, Patel MM, Amin AF (2003) Development of modifi ed release diltiazem $\mathrm{HCl}$ tablets using composite index to identify optimal formulation. Drug Dev Ind Pharm 29: 565-574.

17. Gohel MC, Patel KV, Panchal MK, Doctor BB, Shah PD (1999) Application of simplex lattice design to the preparation of sustained-release diltiazem hydrochloride tablets using modified guar gum. Indian J Pharm Sci 61: 162167

18. Gohel MC, Panchal MK (1999) Formulation optimization of diltiazem-HCl matrix tablets containing modified guar gum using a central composite design. Pharm Pharmacol Commun 5: 331-338.

19. Gohel MC, Patel KV (1997) Formulation optimization of diltiazem hydrochloride matrix tablets containing modified ispaghula husk using factorial design. Drug Dev Ind Pharm 23: 1055-1061.

20. Ahrabi SF, Madsen G, Dyrstad K, Sande SA, Graff ner C (2000) Development of pectin matrix tablets for colonic delivery of model drug ropivacaine. Eur $\mathrm{J}$ Pharm Sci 10: 43-52.

21. Rekhi GS, Nellore RV, Hussain AS, Tillman LG, Malinsowski HJ, et al., (1999) Identifi cation of critical formulation and processing variables for metoprolo tartarate extended release (ER) matrix tablets. J Control Release 59: 327-342.

22. Gohel MC, Jani GK, Patel NK, Gondaliya DP (1998) Optimization of hydrophilic matrix tablet formulation of diclofenac sodium using a mixture design. Pharm Pharmacol Commun 4: 433-438.

23. Singh B, Gupta RK (1997) Optimization of HPMC matrix tablet formulations of diclofenac through response surface methodology. In: Proceedings of 49th Indian Pharmaceutical Congress; Thiruvantha puram, India.

24. Dangprasirt P, Ritthidej GC (1997) Development of diclofenac sodium controlled release solid dispersion tablet using optimization strategy. Drug Dev Ind Pharm 23: 843-848.

25. Pena-Romero A, Poncet M, Jinot J, Chulia D (1988) Statistical optimization of a sustained release form of sodium diclofenac on inert matrices. Part 2 Statistical optimization. Pharm Acta Helv 63: 333-342.

26. Bonferoni MC, Rossi S, Ferrari F, Bertoni M, Bolhuis GK, et al. (1998) On the employment of $\psi$ carrageenan in a matrix system. Part 3. Optimization of a $\psi$ carrageenan- HPMC hydrophilic matrix. J Control Release 51: 231-239.

27. Hariharan M, Gupta V, Price JC (1997) Optimization of sustained-release table formulations: a four component mixture experiment. Pharm Dev Technol 2 365-371.

28. Hussain AS, Yu XQ, Johnson RD (1991) Application of neural computing in pharmaceutical product development. Pharm Res 8: 1248-1252.

29. Geoff roy JM, Fredrickson JK, Shelton JT (1998) A mixture experiment approach for controlling the dissolution rate of sustained release tablet. Drug Dev Ind Pharm 24: 799-806.

30. Bodea A, Leucuta SE (1997) Optimization of hydrophilic matrix tablets using a D-optimal design. Int J Pharm 153: 247-255.
31. Timmins $P$, Delargy AM, Howard JR (1997) Optimization and characterization of a $\mathrm{pH}$ independent extended-release hydrophilic matrix tablet. Pharm Dev Technol 2: 25-31.

32. Takahara J, Takayama K, Nagai T (1997) Multi-objective simultaneous optimization technique based on an artifi cial neural network in sustained release formulations. J Control Release 49: 11-20.

33. Danckwerts MP, Van der Watt JG, Moodley I (1996) The effect of processing variables on the release of ibuprofen and caff eine from controlled-release nonswellable core-in-cup compressed tablets. Drug Dev Ind Pharm 22. 681687

34. Matsumura M, Nakagami H, Yamao T, Takayama K, Nagai T (1994) Compute optimization for the formulation of controlled release theophylline tablet made of micronized low substituted hydroxypropylcellulose and methylcellulose. Chem Pharm Bull 42: 1902-1908.

35. Kristl A, Vojnovic D, Karba R, Mrhar A, Rubessa F (1993) Mixture design of theophylline retard formulation. Int J Pharm 100: 33-40.

36. Joly F, Brossard C (1987) Development of a hydrophilic matrix for theophylline. Part I Physical and mechanical properties of materials and optimization of formulation. STP Pharm. Pratiques 3: 556-568

37. Waaler P, Graffner C, Muller B (1992) Optimization of a matrix tablet formulation using a mixture design. Acta Pharm Nord 4: 9-16.

38. Waaler PJ, Arnesen K, Graff ner C, Muller BW (1992) Optimization of the amount of xanthan gum and guar gum in a matrix tablet formulation using a central composite design. Acta Pharm Nord 4: 291-296.

39. Shah S, Morris J, Sulaiman A, Farhadieh B, Truelove J (1992) Development of misopristol 3 hour controlled release formulations using response surface methodology. Drug Dev Ind Pharm 18: 1079-1098.

40. Franz RM, Sytsma JA, Smith BP, Lucisano LJ. In vitro evaluation of a mixed polymeric sustained release matrix using RSM. J Control Release 5: 159-172.

41. Perez-Marcos B, Iglesias R, Gomez-Amoza JL, Martinez-Pacheo R, Souto C (1991) Mechanical and drug release properties of atenolol-carbomer hydrophilic matrix tablets. J Control Release 17: 267-276.

42. Ortigosa C, Guady D, Jacob M, Puech A (1991) The role of gelucire in the availability of theophylline in semisolid matrix capsules. Pharm Acta Helv 66: 311-315.

43. Li LC, Tu YH (1991) In vitro drug release from matrix tablets containing silicone elastomer latex. Drug Dev Ind Pharm 17: 2197-2214.

44. Li LC, Peck GE (1991) Water based silicone elastomer controlled release tablet film coating. V. A statistical approach. Drug Dev Ind Pharm 17: 27-37.

45. Mesiha MS, Rivera D (1994) Factorial design of phenylpropanolamine prolonged release tablet formulations using fl uid bed dryer granulator. Drug Dev Ind Pharm 20: 31-48.

46. Abdel-Rahman AA, Aboutaleb AE, Stamm A, Abdel-Rahman SI, Samy EM (1992) Optimization of Eudragit or cellulosic polymers ibuprofen sustained release systems using principal component analysis. Bull Pharm Sci 15: 63-82.

47. Fassihi R, Fabian J, Sakr AM (1996) Application of response surface methodology to design optimization in formulation of a typical controlled release system. Drugs made in Germany 39: 122-126.

48. Ratsimbazafy V, Brossard C (1992) Optimization of the release of theophylline derivatives from gelucire matrices. Pharm Acta Helv 67: 166-171.

49. Khattab IS, Abdel-rahman S, Khidr S, Abdel-Hakiem O (2001) Development and optimization of sustained release captopril tablets and capsules. Egyptian J Biotech 10: 432-445.

50. Khan MA, Karnachi AA, Singh SK, Sastry SV, Kislalioglu SM (1995) Controlled release coprecipitates: formulation considerations. J. Control Release 37: 131141.

51. Khan MA, Dib J, Reddy IK (1996) Statistical optimization of ketoprofen Eudragit S 100 coprecipitates to obtain controlled release tablets. Drug Dev Ind Pharm 22: $135-141$

52. Hirata M, Takayama K, Nagai T (1992) Formulation optimization of sustained release tablet of chlorpheniramine maleate by means of extreme vertices design and simultaneous optimization technique. Chem Pharm Bull 40: 741 . 746 
Citation: Jethara SI, Patel MR (2015) Optimizing Oral Controlled Release Drug Delivery Systems using Experimental Designs. Intel Prop Rights 3: 135. doi:10.4172/2375-4516.1000135

Page 6 of 6

53. Boza A, De la Cruz Y, Jordan G, Jauregui-Haza U, Aleman A (2000) Statistical optimization of a sustained-release matrix tablet of lobenzarit disodium. Drug Dev Ind Pharm 26: 1303-1307.

54. Ibric S, Jovanovic M, Duric Z, Parojcic J, Petrovic S, et al. (2003) Artificial neural networks in the modeling and optimization of aspirin extended release tablets with Eudragit $L 100$ as matrix substance. AAPS Pharm SciTech 4: 9-15.

55. Sakr A, Tillotson J (2004) Effect of extended-release polymer concentration and $\mathrm{pH}$ and solubility modifi ers on the release of a weakly acid drug from an extended-release, matrix tablet. In: Proceedings of Annual Meeting of American Association of Pharmaceutical Scientists (AAPS); Maryland, USA

56. Sheng HL, Wang P, Tu JS, Yuan L, Pin QN (1998) Application of artifi cial neural networks for formulation designing of matrix tablets. Zhongguo Yiyao Gongye Zazhi 29: 352-354.
57. Zaghloul AA, Vaithiyalingam SR, Faltinek J, Reddy IK, Khan MA (2001) Response surface methodology to obtain naproxen controlled release tablets from its microspheres with Eudragit L100-55. J. Microencapsul 18: 651-662.

58. Sanchez-Lafuente C, Furlanetto S, Fernandez-Arevalo M, Alvarez-Fuentes J, Rabasco AM, et al. (2002) Didanosine extended-release matrix tablets: optimization of formulation variables using statistical experimental design. Int J Pharm 237: 107-118.

59. Ibric S, Jovanovic M, Duric Z, Parojcic J, Solomun L (2002) The application of generalized regression neural network in the modeling and optimization of aspirin extended release tablets with EudragitR RS PO as matrix substance. J. Control Release 82: 213-222.

60. Grassi M, Vojnovich D, Franceschinis E, Perissutti B (2003) Controlled release from hydrophobic matrices obtained by melt extrusion. In: Proceedings of 30th Annual Meeting of Controlled Release Society; Scotland, UK. 